\title{
The Potential Synergistic Activity of Zolmitriptan Combined in New Self-Nanoemulsifying Drug Delivery Systems: ATR-FTIR Real-Time Fast Dissolution Monitoring and Pharmacodynamic Assessment
}

\author{
Shady M Abd El-Halim (D) \\ Mohamed A Mamdouh (D) \\ Sherif $M$ Eid (D) ${ }^{2}$ \\ Bassant MM Ibrahim (D) ${ }^{3}$ \\ Dina A Aly Labib (D) ${ }^{4}$ \\ Sara M Soliman (D) \\ 'Department of Pharmaceutics and \\ Industrial Pharmacy, Faculty of Pharmacy, \\ October 6 University, 6th of October City, \\ Giza, I2585, Egypt; ${ }^{2}$ Analytical Chemistry, \\ Faculty of Pharmacy, October 6 University, \\ 6th of October City, Giza, I2585, Egypt; \\ ${ }^{3}$ Department of Pharmacology, Medical \\ Research Division, National Research \\ Centre, Giza, I2622, Egypt; ${ }^{4}$ Department \\ of Medical Pharmacology, Faculty of \\ Medicine, Cairo University, Cairo, 1 1559, \\ Egypt
}

Purpose: The current work aimed to overcome the poor permeability and undesirable adverse effects of Zolmitriptan (ZMT) and to increase its efficacy in the treatment of acute migraine by exploiting the synergistic effect of the essential oil, lavender, to fabricate ZMT self-nanoemulsifying drug delivery systems (ZMT-SNEDDS).

Methods: ZMT-SNEDDS were fabricated based on full factorial design $\left(3^{2}\right)$ to statistically assess the impact of oil and surfactant concentrations on the nanoemulsion globule size, zeta potential and percentage drug dissolution efficiency. An ATR-FTIR method was developed and validated for continuous real-time monitoring of ZMT dissolution and permeation. The dose of the optimized ZMT-SNEDDS used in the efficacy study was selected according to the acute toxicity study. The efficacy study was performed on migraineous rats induced by nitroglycerin and was evaluated by the activity cage and thermal tests, electroencephalogram, electroconvulsive stimulation, and biochemical analysis of brain tissue. Finally, histopathological and immunohistochemical examinations of the cerebra were carried out.

Results: Upon dilution, the optimized ZMT-SNEDDS (F5) exhibited nanosized spherical droplets of $19.59 \pm 0.17 \mathrm{~nm}$ with narrow size distribution, zeta potential $(-23.5 \pm 1.17 \mathrm{mV})$ and rapid emulsification characteristics. ATR-FTIR spectra elucidated the complete time course of dissolution and permeation, confirming F5 superior performance. Moreover, ZMT-SNEDDS (F5) showed safety in an acute toxicity study. ZMT concentration in rat brain tissues derived from F5 was lower compared to that of ZMT solution, yet its effect was better on the psychological state, algesia, as well as maintaining normal brain electrical activity and delayed convulsions. It counteracted the cerebral biochemical alternations induced by nitroglycerin, which was confirmed by histopathological examination.

Conclusion: In a nutshell, these findings corroborated the remarkable synergistic efficacy and the high potency of lavender oil-based ZMT-SNEDDS in migraine management compared to the traditional zolmitriptan solution.

Keywords: ZMT-SNEDDS, acute migraine, real-time monitoring, nitroglycerin, activity cage, algesia

Correspondence: Shady M Abd El-Halim Faculty of Pharmacy, October 6 University, Central Axis, Part I/I, Behind 6th of October City Authority, Giza Government, 6th of October City, 12585, Egypt

Tel +20 I I I 9994874

Email shady_mohammed@o6u.edu.eg

\section{Introduction}

Migraine is a unilateral, throbbing recurrent headache, which is a painful neurological disease. Migraine symptoms are often preceded by sensory or motor disturbances 


\section{Graphical abstract}

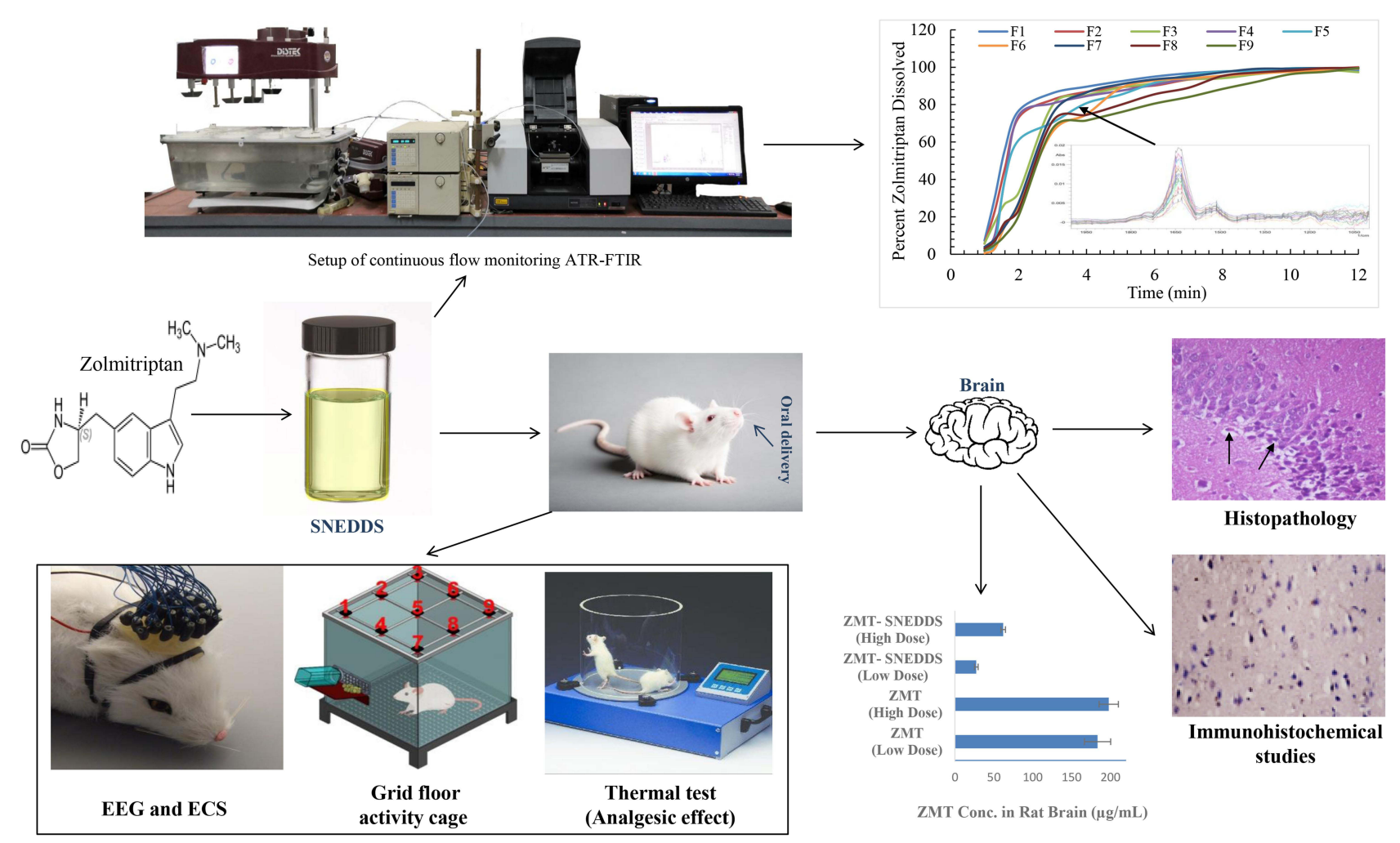

that are referred to as aura. Patients suffering migraines may also experience phonophobia, nausea, vomiting, fever, chills which differentiates it from stress headache. ${ }^{1}$

Migraineurs are more susceptible to develop migraine attacks when given the vasodilator drug Nitroglycerin (NTG). This incidence is correlated to a lower temporal summation threshold with hypersensitivity of the algesic system to NTG. Administration of NTG systemically to rats induces hyperalgesia and migraine-like symptoms similar to those in migraineurs through activation of brain nuclei incorporated in nociceptive transmission and changes in autonomic nervous system responses in rats. ${ }^{2}$

The serotonergic agonists, triptans, are currently the gold standard for the abortive approach in migraine management. Zolmitriptan (ZMT) is a high potency triptan that belongs to the second generation. ZMT, a selective 5-hydroxytryptamine 1B/1D receptor agonist, acts as a cerebro-vasoconstrictor and inhibitor of the release of the pro-inflammatory neuropeptides from trigeminal perivascular nerve endings. It is prescribed in doses of $2.5 \mathrm{mg}$ or $5 \mathrm{mg}$ up to $10 \mathrm{mg} /$ day. $^{3}$
However, it is recommended to reduce the dose in patients with hepatic impairment as this condition may increase the incidence of hypertension as a result of excessive vasoconstriction, due to impairment of ZMT metabolism by hepatic microsomal enzymes. Overdosage of ZMT may cause sedation or increased headache, tachycardia, tingling, pain, chest tightness, nausea, or vomiting. ${ }^{3}$ Hence, it is worthwhile to examine alternative formulation technique that provides the same efficacy in reducing migraine symptoms but can be given in lower doses to mitigate its side effects.

The absolute bioavailability of ZMT is reported to be $40-50 \%$ for the conventional tablets and nasal dosage forms. The reduction in oral bioavailability is attributed to its low permeability, being a BCS class III drug, as well as the hepatic first pass effect. ${ }^{4}$

The challenge of poor oral bioavailability has, for long, triggered the search for a viable fix for this predicament. Lipid-based formulations gained appreciable momentum as a dependable method of delivering drugs that are poorly soluble or permeable. Among those, self-nanoemulsifying drug delivery systems (SNEDDS) have been established as 
an efficient tool for enhancing the oral systemic bioavailability of such drugs. These systems are essentially isotropic blends of the drug, lipids, surface active agents, along with one or more co-emulsifiers. They disperse in the gastrointestinal (GIT) aqueous media in such a fine form where a large surface area is created, which improves drug absorption. ${ }^{5}$

SNEDDS are commonly formulated utilizing vegetable oils or semi-synthetic lipids. Recently, essential oils such as peppermint, lavender, and others have also been probed for SNEDDS formulation, most likely as a result of their potential disparate therapeutic outcomes such as alleviating the associated migraine symptoms of pain and nausea as well as the facile emulsification as compared to vegetable oils. ${ }^{6,7}$

Assessment of a drug's dissolution and permeation from dosage forms involves frequent sample withdrawal for analysis using UV-spectrophotometry, or more commonly HPLC. Such techniques involve numerous solution replacements and conditions re-adjustment resulting in excessive solvent consumption, increased waste time and energy, and the risk of component interference if UV-spectrophotometry is employed. Therefore, the implementation of Attenuated Total Reflection-Fourier Transform Infrared (ATR-FTIR) real-time monitoring is advantageous to overcome these obstacles as it can provide a continuous profile of the dissolved drug concentrations with time. ${ }^{8}$ The FTIR spectrum can reveal unique information about ZMT's molecular structure, which is referred to as a fingerprint for its quantification. ${ }^{9}$

The endeavor of this study is to enhance ZMT permeation through intestinal barriers compared to the drug solution via loading it into SNEDDS, as well as to elucidate the adjuvant effect of the selected essential oil in potentiating the anti-migraine effect of ZMT. In addition, we aim to develop an ATR-FTIR method that could be used for tracking the real-time change in ZMT concentration during its dissolution and permeation testing. The efficacy of ZMT loaded SNEDDS will be compared to oral ZMT solution in an animal model mimicking migraine to assess its effect on the production of the serotonin precursor "tryptophan" and metabolic changes of the brain cells in relation to ZMT concentrations detected in the brain. The comparison will also include the psychological and analgesic effects of both forms in addition to histopathological and immunohistochemical examination of brain tissue.

\section{Methods}

\section{The Investigation of ZMT Solubility in Different Essential Oils}

To select the proper oil phase, the saturated solubility of ZMT in various oils, viz. ginger, lavender and peppermint oils, was determined. Excess ZMT was added to each oil in a stoppered vial, vortexed for $5 \mathrm{~min}$ followed by $72 \mathrm{~h}$ of shaking at $25 \pm 0.5^{\circ} \mathrm{C}$ until equilibrium is reached. Undissolved ZMT was removed by centrifugation at $2500 \mathrm{rpm}$ for $30 \mathrm{~min}$. The supernatant was then filtered via a Millipore $0.45 \mu \mathrm{m}$ filter. The drug concentration in each filtrate was determined using HPLC at $\lambda \max =222$ $\mathrm{nm}$, according to the Champaneria et al method. ${ }^{10}$ The observed retention time for ZMT was $3.5 \mathrm{~min}$.

\section{The Selection of Surfactants and Cosurfactants}

Cremophor $^{\circledR}$ EL [Polyoxyl 35 hydrogenated castor oil $(\mathrm{P} 35 \mathrm{HCO}), \mathrm{HLB}=13.5]$, Labrasol $^{\circledR}(\mathrm{HLB}=12)$, Brij $^{\circledR}$ L4 $(\mathrm{HLB}=9)$ and $\left.\mathrm{Brij}^{\circledR} 93(\mathrm{HLB}=4)\right]$ were tested for their ability to integrate significant volumes of water into oil/ surfactant combinations. A 1:1 w/w ratio of the selected oil was combined with each of the four tested surfactants. Water was then drop-wise titrated while continuously stirred until the mixture turned turbid. The highest percentage of water that could be integrated into the oil/surfactant combination $(\mathrm{O} / \mathrm{S}$ mix) was used to determine which surfactant should be used in the formulation of SNEDDS. The percentage of water incorporated was calculated as follows:

Percent of water incorporated $=\left[\frac{\text { wt.of added water }}{\left(\begin{array}{l}\text { wt.of mixture } \\ + \text { wt.of added water }\end{array}\right)}\right] \times 100$

Co-surfactants were tested for their capacity to boost the selected surfactant's nano emulsification capabilities. At a surfactant to cosurfactant $(\mathrm{S} / \mathrm{CoS})$ ratio of $(1: 1 \mathrm{w} /$ w), the chosen surfactant was coupled with each of the three different cosurfactants (Transcutol $^{\circledR}$ HP, Lauroglycol ${ }^{\mathrm{TM}}$ 90, and Propylene Glycol). The oil and each $\mathrm{S} / \mathrm{CoS}$ mixture were combined at a ratio of $(1: 1 \mathrm{w} /$ $w)$. These combinations were screened the same way the surfactants were screened, and the $\operatorname{CoS}$ that allowed the highest water incorporation was chosen for constructing the ternary phase diagram. ${ }^{11}$ 


\section{Phase Diagram Construction and} Preparation of ZMT Charged SNEDDS

The phase diagram was created to figure out the percentage of components that would result in the formation of a nanoemulsion. ${ }^{12}$ Adequate amounts of each component were weighed into small vials, vortex mixed for $10 \mathrm{~min}$, then gently stirred with heating at $37^{\circ} \mathrm{C}$ to generate a homogeneous isotropic mixture. Thirty-six systems were created and maintained at room temperature for 24 $\mathrm{h}$ before being visually examined. ${ }^{13}$

The phase diagram was also structured in the presence of ZMT $(1 \% \mathrm{w} / \mathrm{w})$ for all the generated SNEDDS to investigate the influence of drug incorporation on the nanoemulsion area. To recognize the effect of dilution on nanoemulsion boundaries, all the prepared systems, with and without drug loading, were diluted 100 times with deionized water and $\%$ transmittance was determined spectrophotometrically at $638 \mathrm{~nm}$ against deionized water as a blank. ${ }^{14}$

Nine ZMT-SNEDDS were selected for further investigations based on the established clear region of the ternary phase diagram where a full factorial design $\left(3^{2}\right)$ was applied to statistically assess the effect of oil and surfactant concentrations (X1 and X2, respectively) on the emulsion's globule size, zeta potential and percentage drug dissolution efficiency. Three levels were assigned to each factor, as presented in (Table 1). The statistical study was followed by the calculation of the desirability to select the optimum formula for further investigations using Design Expert ${ }^{\circledR}$ software (version 7; Stat-Ease, Inc., Minneapolis, MN).

\section{In-vitro Investigations and Optimization of ZMT-Loaded SNEDDS}

\section{Robustness to Dilution and Assessment of \\ Self-Emulsification Efficiency of Various \\ ZMT-SNEDDS}

ZMT-SNEDDS formulae $(0.1 \mathrm{~mL}$ of each), was diluted to $10 \mathrm{~mL}$ with deionized water and the percent transmittance was measured at $638 \mathrm{~nm}$ using deionized water as a blank. In addition, the nanoemulsions were examined for drug precipitation and phase separation, if any. ${ }^{11}$

\section{Assessment of Self-Emulsification Time of Different ZMT-SNEDDS}

The dispersion rate is a measure of the effectiveness of self-emulsification. Using the dissolution apparatus at $50 \mathrm{rpm}$ and temperature $37 \pm 0.5^{\circ} \mathrm{C}$, one $\mathrm{mL}$ of ZMTSNEDDS was introduced to $500 \mathrm{~mL}$ of deionized water. The time for the dispersed SNEDDS to completely vanish was visually tracked. ${ }^{14}$

Determination of Globule Size, Polydispersity Index and Zeta Potential of the Diluted ZMT-SNEDDS

Malvern Zetasizer was used to analyze the globular size, polydispersity index (PDI), and zeta potential. ZMT-SNEDDS were diluted 100 times in deionized water and gently shaken to create nanoemulsions prior to measurement. ${ }^{15}$

In-vitro Dissolution Study of ZMT from the Prepared Systems Using Attenuated Total Reflection-Fourier Transform Infrared

An ATR-FTIR method was implemented to determine the percent of ZMT dissolved relative to time. (Figure S1) shows the circulation setup of the ATR-FTIR continuous

Table I Experimental Runs Independent Variables (Formulation Variables) of the $3^{2}$ Full Factorial Experimental Design

\begin{tabular}{|l|c|c|c|c|c|c|c|}
\hline \multirow{2}{*}{ Formula } & \multicolumn{2}{|c|}{$\begin{array}{c}\text { Factors (Independent } \\
\text { Variables) }\end{array}$} & \multicolumn{3}{|c|}{ Dependent Variables } & \multicolumn{2}{c|}{$\begin{array}{c}\text { PDI } \\
\text { Time (Sec) }\end{array}$} \\
\cline { 2 - 7 } & $\begin{array}{c}\text { XI: Oil } \\
\text { Conc } \\
\text { (\%) }\end{array}$ & $\begin{array}{c}\text { X2: } \\
\text { Surfactant } \\
\text { Conc (\%) }\end{array}$ & $\begin{array}{c}\text { YI: Average } \\
\text { Droplet Size } \\
\text { (nm) }\end{array}$ & $\begin{array}{c}\text { Y2: Zeta } \\
\text { Potential } \\
\text { (mV) }\end{array}$ & $\begin{array}{c}\text { Y3: Dissolution } \\
\text { Efficiency, I2 Min. }\end{array}$ & \\
FI & 10 & 10 & $19.40 \pm 0.51$ & $-27.7 \pm 3.56$ & $82.34 \pm 3.45$ & $0.35 \pm 0.001$ & $40 \pm 0.47$ \\
F2 & 30 & 10 & $27.39 \pm 0.46$ & $-26.8 \pm 1.50$ & $79.89 \pm 2.74$ & $0.35 \pm 0.022$ & $90 \pm 1.25$ \\
F3 & 50 & 10 & $35.05 \pm 0.44$ & $-32.2 \pm 3.76$ & $76.16 \pm 3.18$ & $0.26 \pm 0.023$ & $125 \pm 3.68$ \\
F4 & 10 & 20 & $15.59 \pm 0.17$ & $-23.9 \pm 3.19$ & $79.36 \pm 2.91$ & $0.21 \pm 0.019$ & $51 \pm 2.49$ \\
F5 & 30 & 20 & $19.59 \pm 0.36$ & $-23.5 \pm 1.17$ & $77.56 \pm 1.82$ & $0.29 \pm 0.009$ & $121 \pm 2.51$ \\
F6 & 50 & 20 & $24.28 \pm 0.13$ & $-23.5 \pm 2.62$ & $73.38 \pm 2.77$ & $0.33 \pm 0.013$ & $180 \pm 2.01$ \\
F7 & 10 & 40 & $13.97 \pm 0.06$ & $-17.2 \pm 1.32$ & $76.45 \pm 3.69$ & $0.10 \pm 0.011$ & $303 \pm 3.8$ \\
F8 & 30 & 40 & $14.29 \pm 0.17$ & $-21.1 \pm 1.99$ & $72.20 \pm 3.53$ & $0.17 \pm 0.016$ & $371 \pm 4.52$ \\
F9 & 50 & 40 & $15.84 \pm 0.08$ & $-20.2 \pm 2.53$ & $68.63 \pm 2.91$ & $0.15 \pm 0.016$ & $459 \pm 6.14$ \\
\hline
\end{tabular}


flow system (Pump, dissolution device, FTIR, and computer). The continuous flow starts from the dissolution apparatus vessel where the formula was placed. Samples were pumped in tubes towards the ATR unit using a pulsation pump adjusted at $2 \mathrm{~mL} / \mathrm{min}$. The pumped solution moves towards the ZnSe crystal (ATR unit), which is tightly sealed with a metal cover. This cover permits the solution movement in one direction to be scanned and returned back to the dissolution vessel, as shown in (Figure S1 and Supplementary Video S1).

The circulating system conditions must be optimized, before the measurement of the samples, as follows:

a) Nitrogen gas was used for the removal of air and humidity from the ATR unit.

b) The FTIR software parameters were carefully adjusted as follows: Measurement mode: Absorption, scanning range: $750-4500 \mathrm{~cm}^{-1}$ with automatic scanning for $15 \mathrm{~min}$. SqrTriangle apodization function, the mirror speed is 2.8 , each sample was measured 45 times. The device was adjusted for automatic atmospheric interference correction.

c) The solutions and standards were carefully heated to $37^{\circ} \mathrm{C}$ before each measurement.

d) The solution was pumped at a constant flow rate of ( $2 \mathrm{~mL} / \mathrm{min}$ ) during the experiment. The conditions were stabilized by allowing it to flow for five minutes until all gases that may present in the tubes were removed.

Before starting the circulation, different working concentrations of ZMT $(0.2-12 \mu \mathrm{g} / \mathrm{mL})$ were placed separately in the dissolution vessel, then the flow was started, and the different ZMT spectra were recorded.

Real-time dissolution testing is an essential parameter to be evaluated during drug development and quality control. In order to evaluate ZMT-SNEDDS dissolution profile, samples (500 mg) were filled into hard shell capsules size 00 and placed in a dissolution vessel filled with $500 \mathrm{~mL}$ deionized water. The vessels were continuously stirred at $50 \mathrm{rpm}$ and heated at $37{ }^{\circ} \mathrm{C}$. The circulation was then started, and the solution was pumped towards the FTIR prism, where the samples were continuously scanned, and the spectra were automatically recorded. The efficacy of dissolution in percent $(\% \mathrm{DE})$ was determined for each system based on the equation described by Sharma et al. ${ }^{16}$

\section{Ex-vivo Permeation Study of ZMT from the Optimized ZMT-SNEDDS}

The non-everted rat intestinal sac model was utilized to evaluate the permeation of ZMT from SNEDDS through the intestinal mucosa. Isolated small intestines of sacrificed male Wistar rats (200-250 g) were carefully cleansed using phosphate buffer saline (PBS) and cut into $4 \mathrm{~cm}$ long segments. A definite amount of the optimized SNEDDS was diluted separately with $1 \mathrm{~mL}$ phosphate buffer $(\mathrm{pH}$ 6.8) and filled into the segments. Both ends of the intestines were securely knotted to avoid leakage before being placed in beakers with $50 \mathrm{~mL}$ of phosphate buffer $(\mathrm{pH}$ 6.8). A shaking water bath was used to keep the receptor phase at $37 \pm 0.5^{\circ} \mathrm{C}$ with gentle shaking at $50 \mathrm{rpm} .{ }^{5}$ Data was compared to a ZMT solution in deionized water. Using the ATR-FTIR approach previously stated in the "In-vitro ATR-FTIR Dissolution" section, samples were analyzed for the percent of ZMT permeated relative to time.

\section{Thermodynamic Stability of the Optimized ZMT-SNEDDS}

Three full freeze-thaw cycles were performed on the chosen formula, demonstrating its physical stability as well as its capacity to tolerate thermal stress. ${ }^{17}$

\section{Transmission Electron Microscopy of the Optimized ZMT-SNEDDS}

Transmission electron microscopy (TEM) was used to evaluate the morphology of the optimum formula according to the method mentioned by Soliman et al. ${ }^{18}$

\section{Pharmacological Study of the Optimized ZMT Loaded SNEDDS} Experimental Animals

Adult female Wister albino rats with a body weight range of 180-200 g were obtained from the animal house at the National Research Center (Giza, Egypt). Throughout the investigation, the animals were kept in appropriate laboratory conditions. They were fed standard pellet chow, provided by the animal house at the National Research Centre, and allowed free access to water. All experimental procedures were carried out in accordance with the "Guide for the Care and Use of Laboratory Animals" issued by the Institute of Laboratory Animal Resources (U.S.); Committee on Care and Use of Laboratory Animals; National Institutes of Health (U.S.), and Division of Research Resources, NIH Publication Series. ${ }^{19}$ The animal procedures were approved by Egypt's "National Research Centre's Ethics Committee", with permission certificate registration number (8413042021). 


\section{Acute Toxicity Study of the Optimized ZMT-SNEDDS}

A single dose of ZMT-SNEDDS $(0.045 \mathrm{mg} / \mathrm{kg})$, diluted with one $\mathrm{mL}$ distilled water, was orally administered to five healthy, adult, non-pregnant female rats ( $18 \mathrm{~h}$ fasted). This dose was equivalent to one-tenth of the conventional ZMT solution dose; after converting the human dose to the equivalent rat dose, according to Paget and Barnes. ${ }^{20}$ A similar group served as negative control and was given $1 \mathrm{~mL}$ distilled water once. The rats were observed closely during the first $30 \mathrm{~min}$ after dosing. During the first $24 \mathrm{~h}$ care was taken to report any mortalities, abnormal behavior, bowel habit changes, or abnormal respiration. In addition, any noticeable body weight (bwt) change from baseline bwt during the next fourteen days was also reported. ${ }^{21}$

\section{Efficacy Studies of the Optimized ZMT-SNEDDS}

For the induction of migraine, all the rats, with the exception of the negative control group, received NTG intraperitoneally at a dose of $5 \mathrm{mg} / \mathrm{kg}$ every two days over a nine-day total period (5 total injections) according to the method by Pradhan et al. ${ }^{22}$

Eighty female Wister Albino rats weighing 175-190 $\mathrm{g}$ were equally divided into eight groups, with two control groups; a negative control group where rats received one $\mathrm{mL}$ distilled water orally during the experiment and a positive control group comprising the untreated migraine rats. The treated groups received the treatment orally, one hour after each NTG injection, and the treatment was administered as follows; two groups received conventional ZMT solution in doses of 0.225 and $0.45 \mathrm{mg} / \mathrm{kg}$ (human dose 2.5 and $5 \mathrm{mg} / \mathrm{kg}$ converted to rat dose using Paget's table). Two groups received ZMTSNEDDS in doses $(0.022$ and $0.045 \mathrm{mg} / \mathrm{kg})$, according to the results conducted from the acute toxicity study, and the final two groups received plain SNEDDS in doses of 0.25 and $0.5 \mathrm{~mL}$. Animals were weighed at zero time and at the end of the experiment, with the amount of daily chow fixed throughout the experiment.

Twenty-four hours after the administration of the last treatment dose, animals were subjected to grid floor activity cage testing to assess the effect of the tested agents on the behavior and psychological state during a five-minute test session for each rat. After that, the thermal test was carried out for the evaluation of the optimized SNEDDS analgesic effect. ${ }^{18}$ Detection of the effect of treatment on electrophysiological brain activity was carried out by electroencephalogram and electroconvulsive stimulation.

Electro encephalography (EEG) was performed on all rats under general anesthesia using standard conditions according to the 10-20 international electrode application system. Intermittent photic stimulations were carried out as a provocative technique. ${ }^{23}$

After that, half of the animals in each group were subjected to electroconvulsive stimulation under general anesthesia, ${ }^{24}$ by using single electroconvulsive shock (ECS) of pulse width $3 \mathrm{~ms}$ and frequency of $60-\mathrm{Hz}$ stimuli at a strength of $10 \mathrm{~mA}$. The time elapsed between the application of ECS and the occurrence of convulsions was calculated.

After performing EEG and ECS, all the animals were humanely sacrificed by decapitation under anesthesia. The animals on which ECS was performed were ruled out of the subsequent investigations that involved biochemical assays and histopathological examination.

The estimation of ZMT levels achieved from ZMTSNEDDS and ZMT solution in rats' brains was performed using HPLC. ${ }^{10}$ Structural and compositional changes in rats' brains were determined using FTIR. The obtained group spectrum was normalized and analyzed for the following spectral regions: (i) $\mathrm{NH}-\mathrm{OH}$ region at $3700-3000 / \mathrm{cm}^{-1}$; (ii) $\mathrm{CH}$ stretching region at $3000-2800 / \mathrm{cm}^{-1}$; and (iii) the fingerprint region at $1800-1000 / \mathrm{cm}^{-1}$, which includes the amide I band (1800-1600/ $\left.\mathrm{cm}^{-1}\right)$. The average of the individual spectrum for each group was obtained using Origin Pro 9 software (OriginLab Corporation, Northampton, MA 01060, USA). ${ }^{25}$

To assess the metabolic changes in the brain, samples of soluble brain tissue were diluted to $1 \mathrm{~mL}$ with PBS (pH: 8.2) and measured using UV-spectrophotometry. The spectra were drawn for all groups in the wavelength range $200-340 \mathrm{~nm}^{26}$

\section{Histopathological and Immunohistochemical Examinations of Brain Tissues}

Brain tissue samples were prepared for histopathologic examination, then scored as follows: 0 being normal; 1 , mild damage; 2 , moderate damage and 3 , severe damage. ${ }^{27}$ Neuron-specific enolase (NSE) immunoreactivity was assessed, and the lesions were scored: 0" for absolutely no staining (negativity); "Score 1" when the index was $>10 \%$ slightly immunopositive cells (weak positivity); "Score 2" with a percentage of intense immunopositive neurons between 10 and 30\% (moderate positivity); 
"Score 3" with a percentage of intensely brown neurons $>30 \%$ of the counted cells (strong positivity). ${ }^{28}$

\section{Results and Discussion}

\section{The Investigation of ZMT Solubility in Different Essential Oils}

Higher solubility of the drug in the oil phase is essential to enable higher drug loading and keep the drug solubilized and evade its precipitation upon dilution. The solubility of ZMT was found to be $59.375 \pm 3.72,6.074 \pm 0.54$, and 0.203 $\pm 0.013 \mathrm{mg} / \mathrm{mL}$ in lavender, peppermint, and ginger oils, respectively. Lavender oil was selected for further formulating, as the significantly higher drug solubility $(p<0.001)$ would also allow for the use of lesser amounts of oil in the formulation, and therefore emulsification is achievable utilizing smaller amounts of both the surfactant and cosurfactant. ${ }^{29}$

\section{The Selection of Surfactants and Cosurfactants}

Drugs' solubilizing characteristics may not equally coincide with the surfactant's high affinity for the oil. As a result, the choice of $\mathrm{S} / \mathrm{CoS}$ was driven by the efficient emulsification of lavender oil as well as the ability to solubilize ZMT. Amongst the screened surfactants, P35HCO showed a significantly higher percentage of water incorporation $(p<0.05)$, as seen in (Figure S2), which could be attributed to being the surfactant with the highest HLB. ${ }^{30}$

By promoting the diffusion of the oil into the surfactant molecules' hydrophobic parts, cosurfactants can further lower the interfacial tension with a consequent boost to the fluidity of the interface. ${ }^{11}$ Upon screening of the CoS, Transcutol ${ }^{\circledR}$ HP was able to incorporate a significantly higher proportion of water $(p<0.05)$, when compared to propylene glycol and lauroglycol ${ }^{\mathrm{TM}}$.

\section{Phase Diagram Construction and Preparation of ZMT Charged SNEDDS}

The ternary phase diagram of lavender oil along with $\mathrm{P} 35 \mathrm{HCO} /$ Transcutol $^{\circledR} \mathrm{HP}$ as a S/CoS system was built to define the self-nanoemulsifying area. The diagram exhibited only a nuanced difference in the nanoemulsifying area after loading ZMT. The shaded area in the triangle, depicted in Figure S3, represents the zone in which SNEDDS form nanosized emulsion droplets with the help of gentle agitation. The observed wide area reflects high self-nanoemulsifying ability. These might be attributed to the adsorption of $\mathrm{S} / \mathrm{CoS}$ at the interface, which contributes to boosting the nanoemulsion stability through lowering interfacial energy and offering a mechanical barrier to avoid agglomeration and phase separation. ${ }^{17}$

\section{In-vitro Investigations and Optimization of ZMT Loaded SNEDDS \\ Robustness to Dilution and Assessment of Self-Emulsification Efficiency of Various ZMT-SNEDDS}

The capacity of SNEDDS to undergo dilution with no precipitation and/or phase separation is critical for applicability in drug delivery. Following their dilution, the formed nano-dispersions maintained their transparency with no signs of phase separation or drug precipitation for $24 \mathrm{~h}$ period. This indicated these systems were suited for oral use as they could travel through the GIT in the desirable nano globular form. The prepared systems manifested a high percentage transmittance of over $95 \%$, indicating superior emulsification capacity with nanosized globules. ${ }^{31}$

\section{Assessment of Self-Emulsification Time of Different ZMT-SNEDDS}

Upon dilution, SNEDDS are expected to achieve rapid and complete dispersion under gentle agitation. Dispersion time was dependent on the composition, as seen in (Table 1). At the different oil levels, raising the surfactant concentration had a marked effect on increasing the emulsification time. This is most likely owing to the high viscosity provided by $\mathrm{P} 35 \mathrm{HCO}$, which delays the water penetration into the colloidal or gel phases developed on the surface of the formulation. ${ }^{32}$ A similar effect was observed for increasing the oil concentration, which could be due to the shortage in the surfactant system at larger oil volumes. Analogous trends have been described by other researchers. ${ }^{33,34}$

Determination of Globule Size, Polydispersity Index and Zeta Potential of the Diluted ZMT-SNEDDS

Small droplet size is a hallmark for emulsion stability and the enhancement of drug bioavailability. Smaller droplets dispersed in the GIT would bring forth quicker drug diffusion and improved drug dissolution. ${ }^{17}$ The mean globular size of the diluted systems ranged from $13.97 \pm 0.06 \mathrm{~nm}$ to $35.05 \pm 0.44 \mathrm{~nm}$. Uniform globule size distribution was concluded from the low PDI values that ranged from $0.101 \pm 0.011$ to $0.351 \pm 0.001$ for all formulae. 
Zeta potential identifies the charged surface of the globules, which in general is a pointer towards the physical stability of the emulsion as the electrostatic repulsive forces between the globules guard against coalescence. Upon dilution, SNEDDS comprising lavender oil and P35HCO produced negatively charged emulsions with zeta potential in the range of $-17.23 \pm 1.32 \mathrm{mV}$ to -32.2 $\pm 3.76 \mathrm{mV}$. The fatty acids in the oil phase and/or the surfactant are most likely responsible for the negative charge. Linolenic and linoleic acids account for more than $80 \%$ of the total fatty acids in lavender oil. The main building block of $\mathrm{P} 35 \mathrm{HCO}$ is glycerol polyethylene glycol hydroxy-stearate, which composes the hydrophobic part together with fatty acid glycerol polyglycol esters. ${ }^{35,36}$

(Figure 1) shows the 3D response surface plots and the quantitative linear relationship between the anticipated value of all dependent variables and the resultant globule size, Zeta potential, and percent RE responses.

ANOVA analysis revealed a significant reduction in globule size $(p<0.0001)$ that coincided with raising the surfactant concentration from $10 \%$ to $40 \%$. The observed decrease could be attributed to the further lowering in the interfacial tension as the amount of surfactant is raised along with the accompanying decrease in the free energy that could cause the droplets to be deformed or disrupted. Furthermore, the formed surfactant film at the interface is more closely packed, thus hindering droplet coalescence and augmenting the emulsion stability. ${ }^{37}$ On the other hand, raising the oil concentration from $10 \%$ to $50 \%$ brought about a significant increase in globule size $(p<0.0001)$. This might be explicable by a shortage in the emulsifier at the interface at higher oil levels.
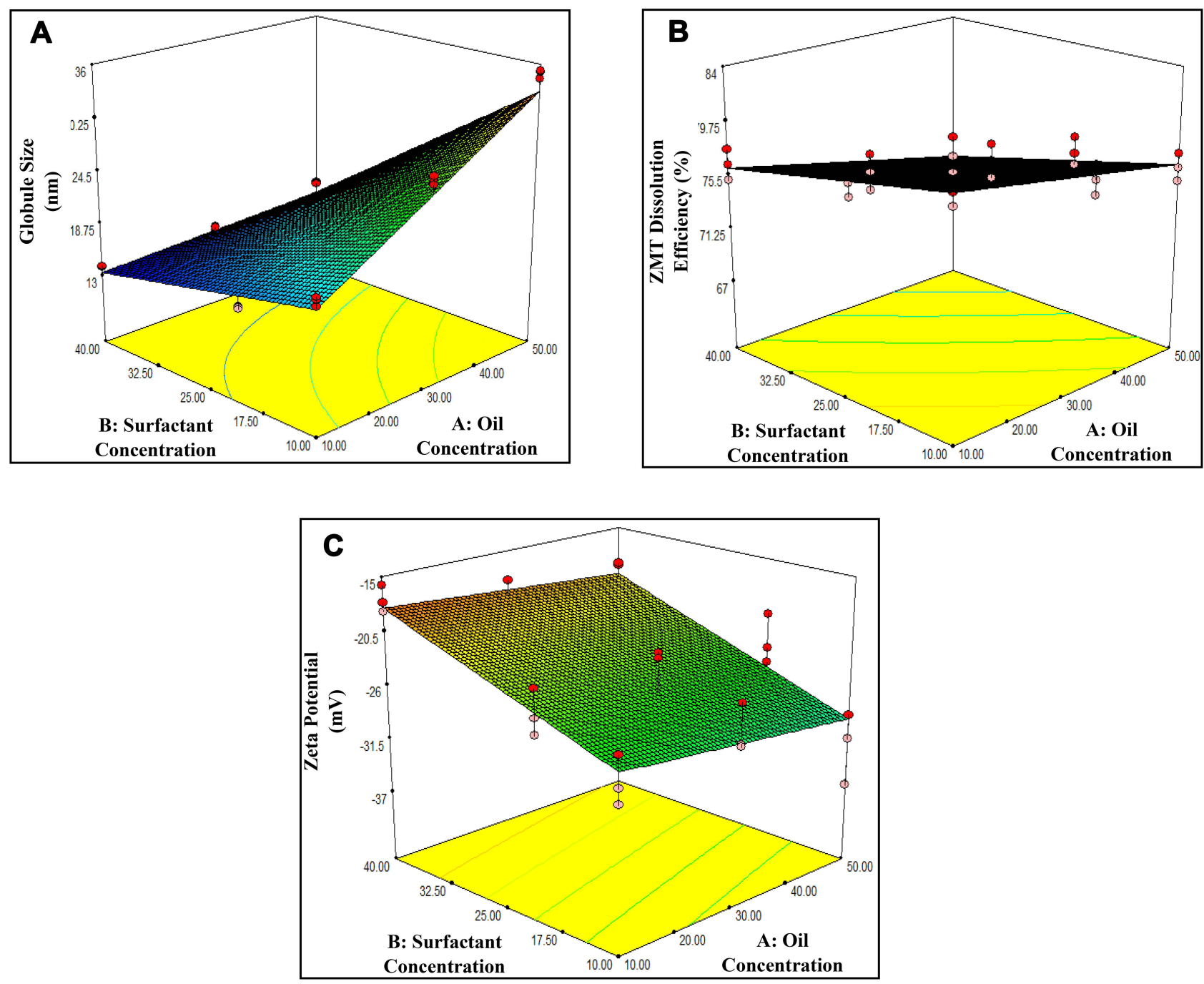

Figure I 3D response surface plots and the quantitative linear relationship between resultant (A) Globule size, (B) \% Zolmitriptan dissolution efficiency and (C) Zeta potential with that of the predicted value of all dependent variables. 
Additionally, the higher oil content may have resulted in emulsions with higher viscosities, thereby reducing the emulsification efficiency. ${ }^{38}$

Zeta potential statistical analysis revealed a nonsignificant effect of oil concentration $(p=0.176)$. In contrast, higher surfactant levels significantly lowered the zeta potential value $(p<0.0001)$. Similar observations were reported on the effect of non-ionic surfactants on lowering zeta potential values above a critical concentration due to the expulsion of hydroxyl groups from the o/w interface, which can reduce the surface potential. ${ }^{37}$

In-vitro Dissolution Study of ZMT from the Prepared Systems Using Attenuated Total Reflection-Fourier Transform Infrared

Zolmitriptan is an anti-migraine drug, so fast dissolution is an essential requirement. Conventional analysis methods such as HPLC require frequent sampling and continuous replacement of the withdrawn solution, so continuous monitoring is advantageous as it can provide a complete real-time profile of the dissolution pattern of the active pharmaceutical agent. The method selectivity is enhanced by the utilization of FTIR real-time monitoring of the drug concentration due to the fact that FTIR spectra are considered as fingerprints for the molecules as they show the characteristic functional groups in the form of bands that confirm the structure ${ }^{39}$ (Figure 2A). ZMT is $\quad(4 \mathrm{~S})-4-(\{3-[2-($ dimethylamino $) e t h y l]-1 \mathrm{H}-$ indol-5-yl $\}$ methyl)-1,3-oxazolidin-2-one and its FTIR spectrum shows the characteristic peaks of its structure, N-H stretching at $3380 \mathrm{~cm}^{-1}$, C-H stretching at $2926 \mathrm{~cm}^{-1}$, and $\mathrm{C}=\mathrm{O}$ stretching at $1738 \mathrm{~cm}^{-1}$.

The developed real-time ATR-FTIR method was validated according to $\mathrm{ICH}$ guidelines by assessment of the following parameters:

a- Linearity and sensitivity: The obtained ZMT spectra were baseline corrected then the characteristic ZMT peak at $1745 \mathrm{~cm}^{-1}$ was selected for calibration (Figure 2A). The relationship between ZMT concentration and absorption was found to be linear as shown in Beer's plot (Figure 2B), within a concentration range of $(0.2-12 \mu \mathrm{g} /$ $\mathrm{mL}$ ) with a small intercept (0.0005), Slope (0.0001), and correlation coefficient of (0.9891).

b- Accuracy and precision: The developed method accuracy was found to be $98.7 \%$, as ensured by applying the Beer-Lambert law for the quantification of different blind ZMT concentrations. The method repeatability (Intraday precision) was determined by analyzing three different ZMT concentrations three times within the same day, where the calculated RSD was 0.345 . The same procedure was applied for the determination of ZMT concentrations during three different days, and the RSD was 0.946 .

c- Robustness: The developed FTIR method was found to be robust and not affected by slight variations of the method parameters, such as the effect of flow rate fluctuation, which was studied by intentional change of the flow rate by $\pm 0.1 \mathrm{~mL} /$ min. Also, the effect of temperature fluctuation was studied by \pm 0.5 change in dissolution temperature. The method was found to be stable and was not significantly affected by these changes, which ensured the method's robustness.

d- Selectivity: FTIR spectrum is considered a fingerprint for each molecule, indicating its characteristic active functional groups, and thereby confirming its identity. So, by monitoring the obtained peaks, the identity of ZMT can be confirmed. Also, the overlay plot of the plain SNEDDS (formula without ZMT) and pure ZMT confirm the selectivity of the method towards ZMT, as shown in (Figure S4).

(Figure 3A) depicts the results of ZMT dissolution from the different formulations in deionized water. All the prepared SNEDDS exhibited a rapid and almost complete drug dissolution within the first 10 minutes. The rapid dissolution could be credited to the rapid emulsification induced by the lower surface free energy of the system and the greater surface area caused by the small size of the globules. ${ }^{40}$ ANOVA analysis revealed that both, the oil and surfactant concentrations significantly affected the $\% \mathrm{DE}(p<0.0001)$, which ranged from $68.67 \pm 1.4 \%$ to $82.37 \pm 1.2 \%$. The $\% \mathrm{DE}$ is directly influenced by globule size, which is in turn affected by the variation in oil concentrations, as discussed earlier.

Also, the increase in surfactant concentration would slow down the emulsification process due to noteworthy increases in the systems' viscosity and thus retard the drug dissolution. $^{32}$ The obtained dissolution results were in accordance with the emulsification times, where systems with faster emulsification time exhibited the highest dissolution efficiency. According to Design-Expert ${ }^{\circledR}$ software, the optimized formula was analyzed based on the following set of criteria; the oil concentration at $30 \%$, globule size $<20 \mathrm{~nm}$, $\mathrm{ZP}$ in range, and maximum \%DE. Accordingly, F5 was selected as the optimized SNEDDS, with a desirability value of 0.632 . Figure $3 \mathrm{~B}$ details the gradual increase in ZMT concentration from F5 till its complete dissolution.

\section{Ex-vivo Permeation Study of ZMT from the Optimized ZMT-SNEDDS}

Relying solely on the in-vitro dissolution data might not be sufficient as a successful predictor of oral absorption and 

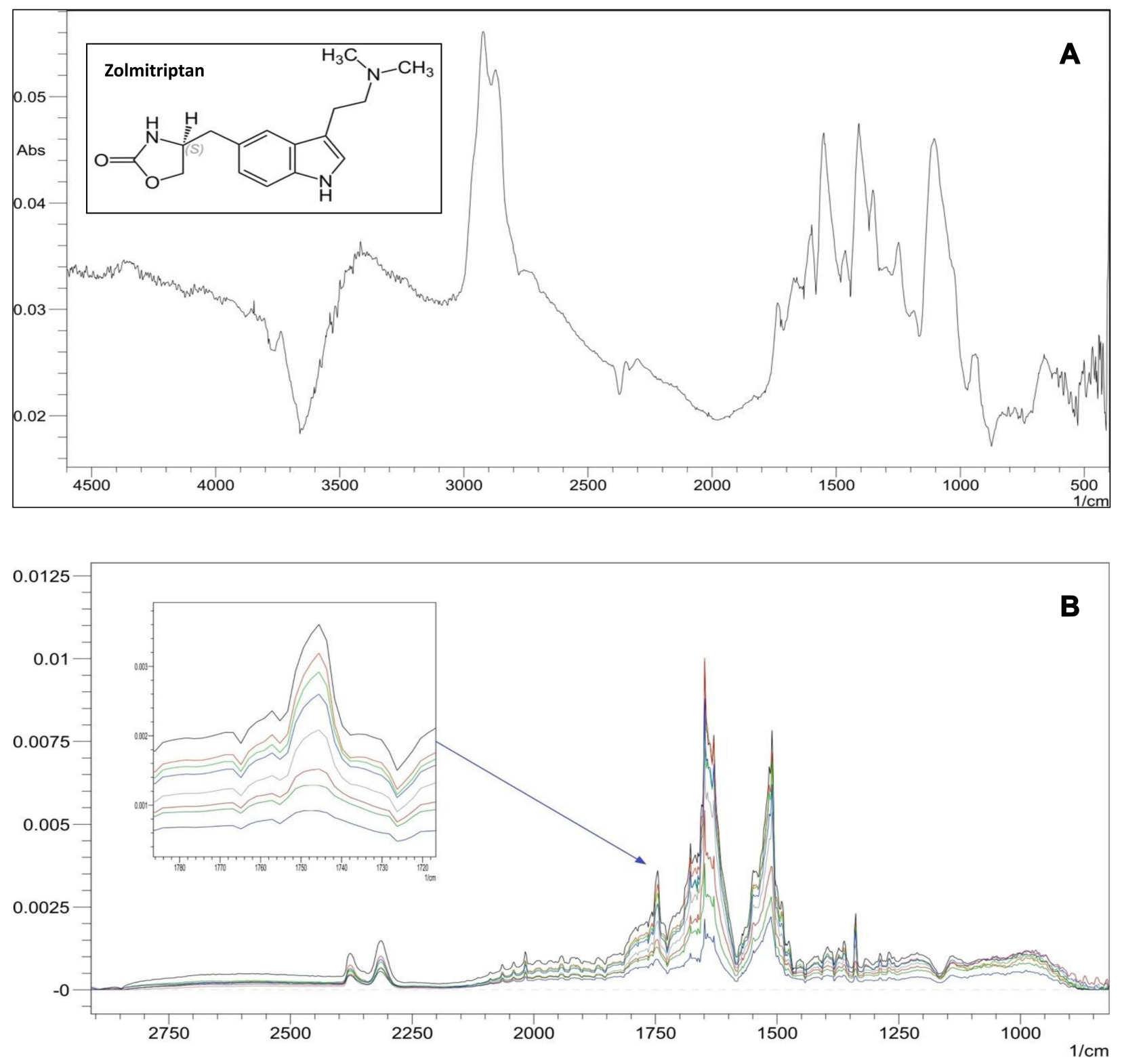

Figure 2 FTIR spectrum of: (A) Zolmitriptan structure and its characteristic peaks and (B) Zolmitriptan calibration concentrations $(0.2-12 \mu g / m L)$ and the inset shows the selected peak for calibration.

in-vivo behavior. Permeation studies, carried out through excised living tissues, could provide valuable data pertaining to the rate and extent of drug absorption. ${ }^{33}$

SNEDDS F5 exhibited an evident boost in ZMT permeation compared to that of ZMT solution, as shown in (Figure S5). The notable difference between the two drug forms could be ascribed to the formed nanosized emulsions being colloidal carriers, which have been acknowledged to enhance the permeation of drugs formulated in SNEDDS and to the inherent permeation enhancing effects of the used excipients via alteration of membrane fluidity which allows for increased diffusion. ${ }^{41}$

\section{Thermodynamic Stability of the Optimized ZMT-SNEDDS}

Exposing the formula of choice (F5) to three freeze-thaw cycles did not exhibit any signs of instability, revealing the stability of the system. There was no phase separation or drug precipitation upon visual inspection, and statistical analysis indicated no significant variation in globule size, zeta potential and $\% \mathrm{DE}(P>0.05)$. 


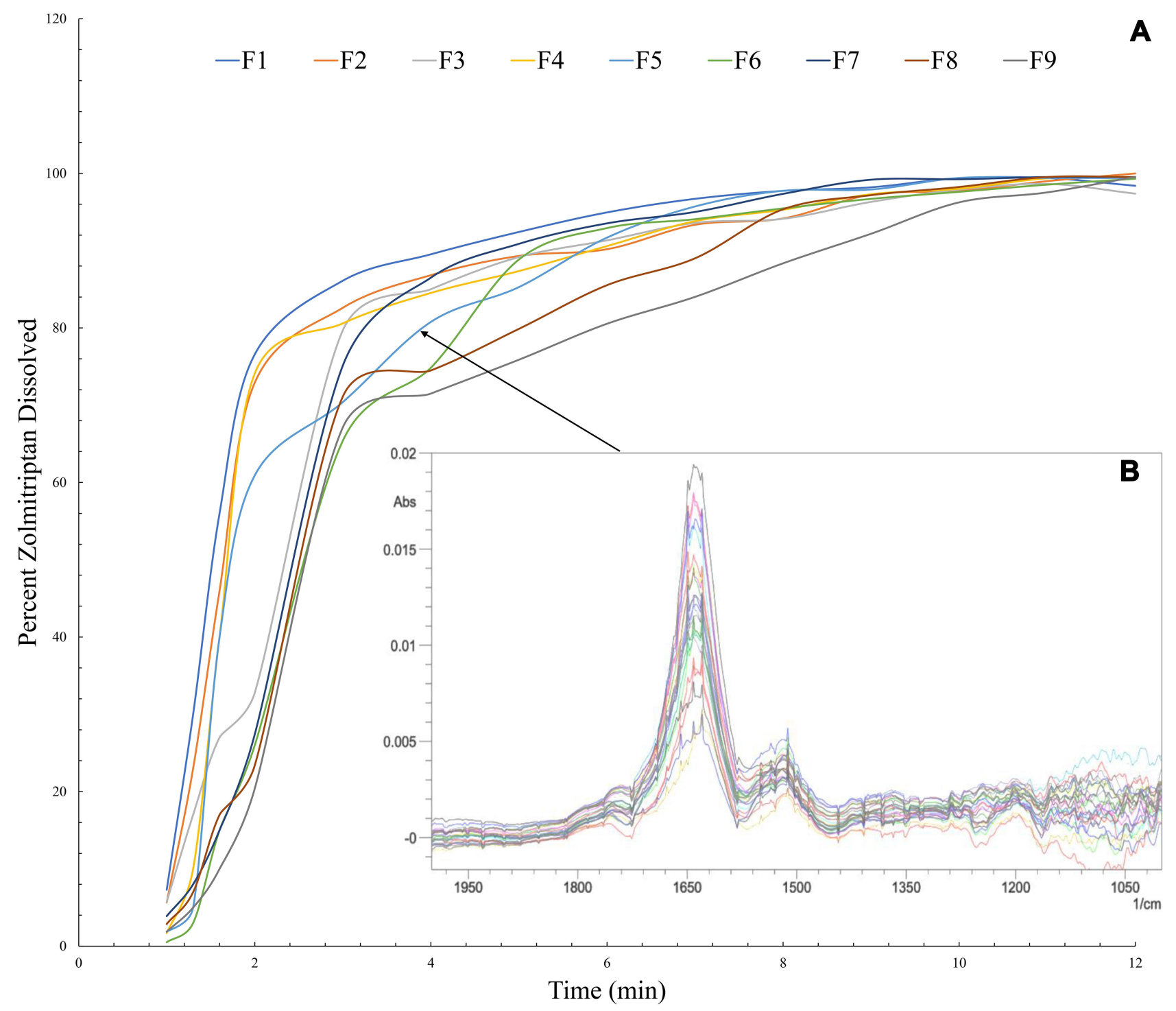

Figure 3 In-vitro Zolmitriptan dissolution: (A) Percentage Zolmitriptan dissolved from different formulations in deionized water and (B) FTIR spectra illustrating the change of Zolmitriptan concentration dissolved from F5 with time.

Transmission Electron Microscopy of the Optimized ZMT-SNEDDS

As shown in (Figure S6), TEM of the reconstituted F5 SNEDDS revealed spherical discrete oil globules with diameters in the range of $19 \mathrm{~nm}$, which coincided with the results obtained using Zetasizer.

\section{Pharmacological Study of the Optimized ZMT Loaded SNEDDS \\ Acute Toxicity Study of the Optimized ZMT-SNEDDS}

Results of the Acute Toxicity study revealed no mortalities among rats within 14 days of administration of ZMTSNEDDS and no changes in bowel habits or behavior of rats. Also, body weights of rats given ZMT-SNEDDS were within the normal range, showing an increase of 3.35\% from baseline bwt before giving ZMT-SNEDDS, which is relatively consistent with the amount of food consumed and is considered normal for the age and duration of the experiment. However, it was significantly less than the negative control (Table 2).

Histopathologic examination of the renal tissue showed normal glomerular structure and intact tubular epithelial lining (Figure S7A). Those of the liver showed normal hepatic lobule histological structure (Figure S7B). All these findings denoted that ZMT-SNEDDS could be used in preclinical studies within safety margins of conventional selective serotonin agonist ZMT. 
Table 2 Effect of Treatment on Body Weight (Bwt) in Acute Toxicity and Efficacy Studies

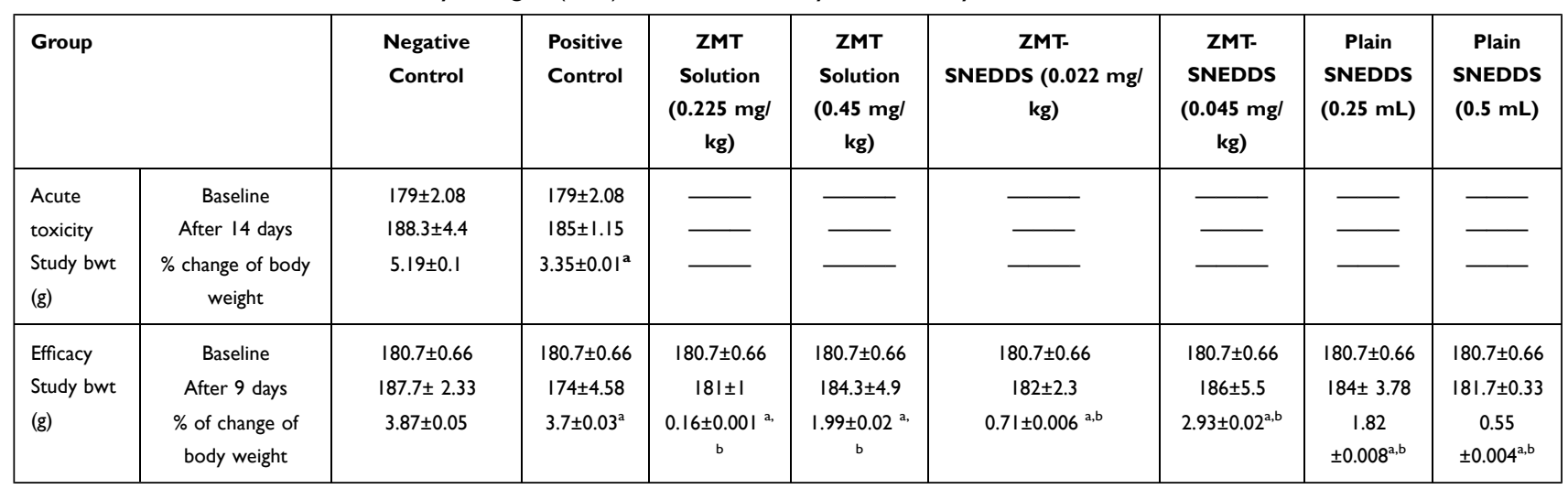

Notes: $\mathrm{N}=5$ for acute toxicity study, $\mathrm{N}=10$ for efficacy study. Results of body weight of rats (bwt) expressed as means of $\mathrm{g} \pm \mathrm{S}$.E. Statistical analysis was done using One-way analysis of variance ANOVA followed by Tukey Kramer multiple comparisons test. Difference was considered significant at $(P<0.000 \mathrm{I})$. ${ }^{\mathrm{a} S i g n i f i c a n t l y ~ d i f f e r e n t ~ f r o m ~ n e g a t i v e ~}$ control, 'Significantly different from positive control.

Therefore, the acute toxicity study confirmed that ZMT-SNEDDS is non-toxic in a dose of $0.045 \mathrm{mg} / \mathrm{kg}$. Accordingly, the selected doses for performing the efficacy study of ZMT-SNEDDS were 0.0225 and $0.045 \mathrm{mg} / \mathrm{kg}$.

\section{Efficacy Studies of the Optimized ZMT-SNEDDS}

Regarding the Efficacy study in the present work, The negative control group rats which received only distilled water throughout the experiment showed a mild increase in bwt of $3.87 \%$, while the positive control group showed a significant reduction of bwt of rats by $3.7 \%$ of baseline bwt. All treated groups showed a significant increase in \% bwt of baseline weight when compared to the positive control group, but still, it was significantly less than that of the negative control group, which is most probably due to digestive system side effects such as dyspepsia and nausea that occur as a part of serotonin syndrome endured by patients treated with triptans including $\mathrm{ZMT}^{42}$ (Table 2).
The behavioral and sensation assessments were carried out by means of both; ambulation test using the grid floor activity cage to assess the rats' psychological and evaluating the integrity of peripheral sensations by means of the hot plate test. The negative control group recorded 99.5 movements during the five minutes duration of the grid floor activity test, and assessment of algesia by using the hot plate revealed intact sensations because the rats' response to temperature adjusted at $52{ }^{\circ} \mathrm{C}$ was rapid, as they licked their paws after 9 seconds, denoting normal withdrawal reflex in response to heat.

On the other hand, the positive control group developed migraine-like symptoms in the form of a significant reduction in movements across the grid floor activity cage, to be $59.79 \%$ less than that of the negative group (Table 3 ), denoting loss of interest or a state of psychological indifference as in cases of depression which accompanies

Table 3 Comparison of the Effects of Treatment with Selective Serotonin Agonist Zolmitriptan (ZMT) vs ZMT-SNEDDS and Its Plain Preparation Containing Lavender Oil on Psychological State Tested by Using the Grid Floor Activity Cage and Their Analgesic Effect Tested by Using Hot Plate Thermal Test

\begin{tabular}{|c|c|c|c|c|c|c|c|c|c|}
\hline \multicolumn{2}{|l|}{ Group } & \multirow{2}{*}{$\begin{array}{l}\text { Negative } \\
\text { Control }\end{array}$} & \multirow{2}{*}{$\begin{array}{l}\text { Positive } \\
\text { Control } \\
40 \pm 2.08^{\mathrm{a}}\end{array}$} & \multirow{2}{*}{$\begin{array}{c}\text { ZMT } \\
\text { Solution } \\
\left(\begin{array}{c}\mathbf{0 . 2 2 5} \mathbf{~ m g} / \\
\mathbf{~ k g})\end{array}\right. \\
85.5 \pm 1.25^{\mathrm{a}, \mathrm{b}, \mathrm{c}}\end{array}$} & \multirow{2}{*}{$\begin{array}{c}\text { ZMT } \\
\text { Solution } \\
(0.45 \mathbf{~ m g} / \mathbf{~ k g}) \\
98 \pm 3.71^{\mathrm{b}, \mathrm{c}, \mathrm{d}}\end{array}$} & \multirow{2}{*}{$\begin{array}{c}\text { ZMT- } \\
\text { SNEDDS } \\
(\mathbf{0 . 0 2 2} \mathbf{~ m g / k g )} \\
86.5 \pm 2.55^{\mathrm{a}, \mathrm{b}, \mathrm{c}}\end{array}$} & \multirow{2}{*}{$\begin{array}{c}\text { ZMT- } \\
\text { SNEDDS } \\
(\mathbf{0 . 0 4 5} \mathbf{~ m g / k g )}) \\
99 \pm 2.27^{\mathrm{b}, \mathrm{c}, \mathrm{d}}\end{array}$} & \multirow{2}{*}{$\begin{array}{c}\text { Plain } \\
\text { SNEDDS } \\
(0.25 \mathrm{~mL}) \\
63.58 \pm 1.84^{\mathrm{a}, \mathrm{b}}\end{array}$} & \multirow{2}{*}{$\begin{array}{c}\text { Plain } \\
\text { SNEDDS } \\
(0.5 \mathrm{~mL}) \\
\begin{array}{c}83.67 \pm 4.17 \\
\mathrm{a}, \mathrm{b}, \mathrm{c}\end{array}\end{array}$} \\
\hline $\begin{array}{l}\text { Activity } \\
\text { Cage }\end{array}$ & $\begin{array}{c}\text { Number of } \\
\text { movements } / 5 \\
\text { minutes }\end{array}$ & & & & & & & & \\
\hline $\begin{array}{l}\text { Hot } \\
\text { Plate }\end{array}$ & $\begin{array}{l}\text { Onset in } \\
\text { seconds }\end{array}$ & $9 \pm 0.4$ & $6.5 \pm 0.64$ & $12.18 \pm 0.73^{b}$ & $12.33 \pm 0.96^{b}$ & $9.86 \pm 0.5 \mathrm{I}^{\mathrm{d}}$ & $13.98 \pm\left.\right|^{\mathrm{a}, \mathrm{b}}$ & $10.9 \pm 1.12^{b}$ & $10.6 \pm 0.22^{b}$ \\
\hline
\end{tabular}

Notes: $\mathrm{N}=10$. Results of grid floor activity cage for psychological state assessment were expressed as means of number of movements/5 minutes \pm S.E. Results of hot plate test for algesia were expressed as means of seconds elapsed before licking the paw \pm S.E. Statistical analysis was done using One-way analysis of variance ANOVA followed by Tukey Kramer multiple comparisons test. Difference was considered significant at $(P<0.05) .{ }^{a}$ Significantly different from negative control, ${ }^{\text {b }}$ Significantly different from positive control, 'Significantly different from plain formula low dose, 'Significantly different from plain formula high dose. 
severe pain. ${ }^{43}$ Moreover, the latency period elapsed till the rats licked their paws in the hot plate test was less than that of the negative control group by $27.77 \%$ (Table 3 ), indicating a form of neuropathic pain that occurs due to lesions in the nervous system. ${ }^{44}$

The occurrence of pain in association with depression is explained by the interrelation of pro-inflammatory cytokines and reduced serotonin in the brain. ${ }^{45}$ This explains the relation between the findings of the hot plate test and the activity cage test in the rat model of migraine in our study. It also explains the subsequent improved results of these tests for rats treated with serotonin agonist either as ZMT solution or ZMT-SNEDDS; as the movements of rats increased significantly for the treated rats compared to the positive control group to be more by $113.75,145,116.25$, $147.5,58.95$ and $109.17 \%$ for ZMT solution (0.225 and $0.45 \mathrm{mg} / \mathrm{kg}$ ), ZMT-SNEDDS (0.022 and $0.045 \mathrm{mg} / \mathrm{kg}$ ) and plain SNEDDS containing lavender oil $(0.25$ and $0.5 \mathrm{~mL})$, respectively. It is noteworthy that the highest increase in ambulation was observed for the groups treated with high doses of both ZMT solution and ZMT-SNEDDS (Table 3).

In addition, the latency for paw licking in hot plate increased significantly compared to positive control group by $87.38,89.69,51.69,115.07,67.69$ and $63.07 \%$ for ZMT solution $(0.225$ and $0.45 \mathrm{mg} / \mathrm{kg})$, ZMT-SNEDDS $(0.022$ and $0.045 \mathrm{mg} / \mathrm{kg})$ and plain SNEDDS containing lavender oil $(0.25$ and $0.5 \mathrm{~mL})$, respectively. It is obvious that ZMT-SNEDDS high dose exhibited the highest analgesic effect (Table 3). The analgesic effect of lavender was explained by Sanna et al, who stated that lavender oil administered to mice in a single dose of $100 \mathrm{mg} / \mathrm{kg}$ alleviated neuropathic pain and its efficacy was comparable to that of pregabalin. They attributed the effect of lavender oil to the marked reduction in inducible nitric oxide synthetase level in the nervous system and the marked reduction of ERK1, ERK2, and JNK1 phosphorylation, in addition to the inhibition of the endocannabinoid degradation enzymes" fatty acid amide hydrolase". 46

When electrical signaling of the brain was assessed by EEG for further investigations of the effect of treatment with ZMT-SNEDDS and plain SNEDDS containing lavender in comparison to ZMT solution, the background activity for all groups was within the normal alpha range. There were no definite focal or paroxysmal discharges and no evidence of slowing or fast activities denoting normal brain electrical signaling (Table 4).

ECS was also done for the confirmation of the previously mentioned in-vivo findings as the delay in the onset of convulsions in response to ECS denotes normal activity. The negative control group exhibited the longest latency period among all tested groups, as the rats started mild seizures after 12 seconds of exposure to ECS single shock, but the result was not significantly different from other groups (Table 4).

HPLC assay was used to detect the concentration of ZMT that reached the brain from the solution and SNEDDS when given in high and low doses to correlate the concentration in the brain with the pharmacological effect achieved as well as the histopathological and histochemical parameters. The concentration of ZMT achieved from SNEDDS low dose was $85 \%$ less than that attained from ZMT low dose solution. The concentration of ZMT from SNEDDS high dose was less than that from ZMT high dose solution by $68.61 \%$. However,

Table 4 Comparison of the Effects of Treatment with Selective Serotonin Agonist Zolmitriptan (ZMT) vs ZMT-SNEDDS and Its Plain Preparation Containing Lavender Oil on Electrical Signaling and Seizure Onset in the Brain Investigated by Electro Encephalogram (EEG) and Electroconvulsive Shock Stimulation Test (ECS)

\begin{tabular}{|c|c|c|c|c|c|c|c|c|c|}
\hline \multicolumn{2}{|c|}{ Group } & \multirow{2}{*}{$\begin{array}{c}\text { Negative } \\
\text { Control } \\
8 \pm 0.5\end{array}$} & \multirow{2}{*}{$\begin{array}{l}\text { Positive } \\
\text { Control } \\
13 \pm 0.5^{\mathrm{a}}\end{array}$} & \multirow{2}{*}{$\begin{array}{c}\text { ZMT } \\
\text { Solution } \\
(0.225 \\
\mathrm{mg} / \mathrm{kg}) \\
\mathrm{II} \pm 0.3^{\mathrm{a}}\end{array}$} & \multirow{2}{*}{$\begin{array}{c}\text { ZMT } \\
\text { Solution } \\
(0.45 \\
\mathbf{m g} / \mathbf{k g}) \\
\begin{array}{c}10 \pm 0.58^{\mathrm{b}, c}, \\
\mathrm{~d}\end{array}\end{array}$} & \multirow{2}{*}{$\begin{array}{c}\text { ZMT- } \\
\text { SNEDDS }(\mathbf{0 . 0 2 2} \mathbf{~ m g} / \mathbf{k g}) \\
12.33 \pm 0.33^{\mathrm{a}}\end{array}$} & \multirow{2}{*}{$\begin{array}{c}\text { ZMT- } \\
\text { SNEDDS } \\
(\mathbf{0 . 0 4 5} \\
\mathbf{m g} / \mathbf{k g}) \\
12.67 \pm 0.3^{\mathrm{a}}\end{array}$} & \multirow{2}{*}{$\begin{array}{c}\text { Plain } \\
\text { SNEDDS } \\
(0.25 \mathrm{~mL}) \\
11.67 \pm 0.6^{\mathrm{a}}\end{array}$} & \multirow{2}{*}{$\begin{array}{c}\text { Plain } \\
\text { SNEDDS } \\
(0.5 \mathrm{~mL}) \\
13 \pm 0.5^{\mathrm{a}}\end{array}$} \\
\hline EEG & $\begin{array}{l}\text { Cycles/ } \\
\text { seconds }\end{array}$ & & & & & & & & \\
\hline ECS & $\begin{array}{c}\text { Onset } \\
\text { in } \\
\text { seconds }\end{array}$ & 12 & $10 \pm 1$ & $9.5 \pm 0.5$ & $11.5 \pm 0.5$ & $9.5 \pm 0.5$ & $9.5 \pm 0.5$ & 10 & 10 \\
\hline
\end{tabular}

Notes: $\mathrm{N}=5$. Results of EEG were expressed as means of number of cycles/seconds \pm S.E. Results of ECS were expressed as means of seconds elapsed before seizures occured \pm S.E. Statistical analysis was done using One-way analysis of variance ANOVA followed by Tukey Kramer multiple comparisons test. Difference was considered significant at $(P<0.05)$. a Significantly different from negative control, bSignificantly different from positive control, 'Significantly different from ZMT-SNEDDS low dose, ${ }^{\mathrm{d}}$ Significantly different from plain formula low dose. 
Table 5 Level of Zolmitriptan (ZMT) in Brain Homogenate of Rats Receiving Conventional Therapy and ZMT-SNEDDS Measured by HPLC $(\mu \mathrm{g} / \mathrm{mL})$

\begin{tabular}{|c|c|c|c|c|c|c|c|c|}
\hline Group & $\begin{array}{c}\text { Negative } \\
\text { Control }\end{array}$ & $\begin{array}{l}\text { Positive } \\
\text { Control }\end{array}$ & $\begin{array}{c}\text { ZMT } \\
\text { Solution } \\
(0.225 \mathrm{mg} / \mathrm{kg})\end{array}$ & $\begin{array}{c}\text { ZMT } \\
\text { Solution } \\
(0.45 \mathrm{mg} / \mathrm{kg})\end{array}$ & $\begin{array}{c}\text { ZMT- } \\
\text { SNEDDS } \\
(0.022 \mathrm{mg} / \mathrm{kg})\end{array}$ & $\begin{array}{c}\text { ZMT- } \\
\text { SNEDDS } \\
(0.045 \mathrm{mg} / \mathrm{kg})\end{array}$ & $\begin{array}{c}\text { Plain } \\
\text { SNEDDS } \\
(0.25 \mathrm{~mL})\end{array}$ & $\begin{array}{l}\text { Plain } \\
\text { SNEDDS } \\
(0.5 \mathrm{~mL})\end{array}$ \\
\hline $\begin{array}{l}\text { Concentration of } \mathrm{ZMT} \text { in } \\
\text { brain Homogenate }(\mu \mathrm{g} / \\
\mathrm{mL})\end{array}$ & $\longrightarrow$ & - & $183.3 \pm 16.87^{a}$ & $197.8 \pm 12.28^{a}$ & $27.48 \pm 2.37^{\mathrm{b}, \mathrm{c}}$ & $62.07 \pm 2.93^{\mathrm{a}, \mathrm{b}, \mathrm{c}}$ & $\longrightarrow$ & - \\
\hline
\end{tabular}

Notes: $N=5$. Results of HPLC were expressed as means of level of ZMT ( $\mu \mathrm{g} / \mathrm{mL})$ in brain tissue homogenates \pm S.E. Statistical analysis was done using One-way analysis of variance ANOVA followed by Tukey Kramer multiple comparisons test. Difference was considered significant at $(P<0.05)$. ${ }^{a}$ Significantly different from negative control, bSignificantly different ZMT low dose, 'Significantly different from ZMT high dose.

the effects of the low and high doses of ZMT from ZMTSNEDDS versus those of ZMT solution on in-vivo parameters were not significantly different (Table 5). Expectedly, there was no evidence of ZMT in brain tissue homogenates of the negative control, positive control, or plain treated groups as they did not receive the drug (Table 5).

FTIR spectroscopy is a strongly reliable technique to investigate the structural, conformational, and functional

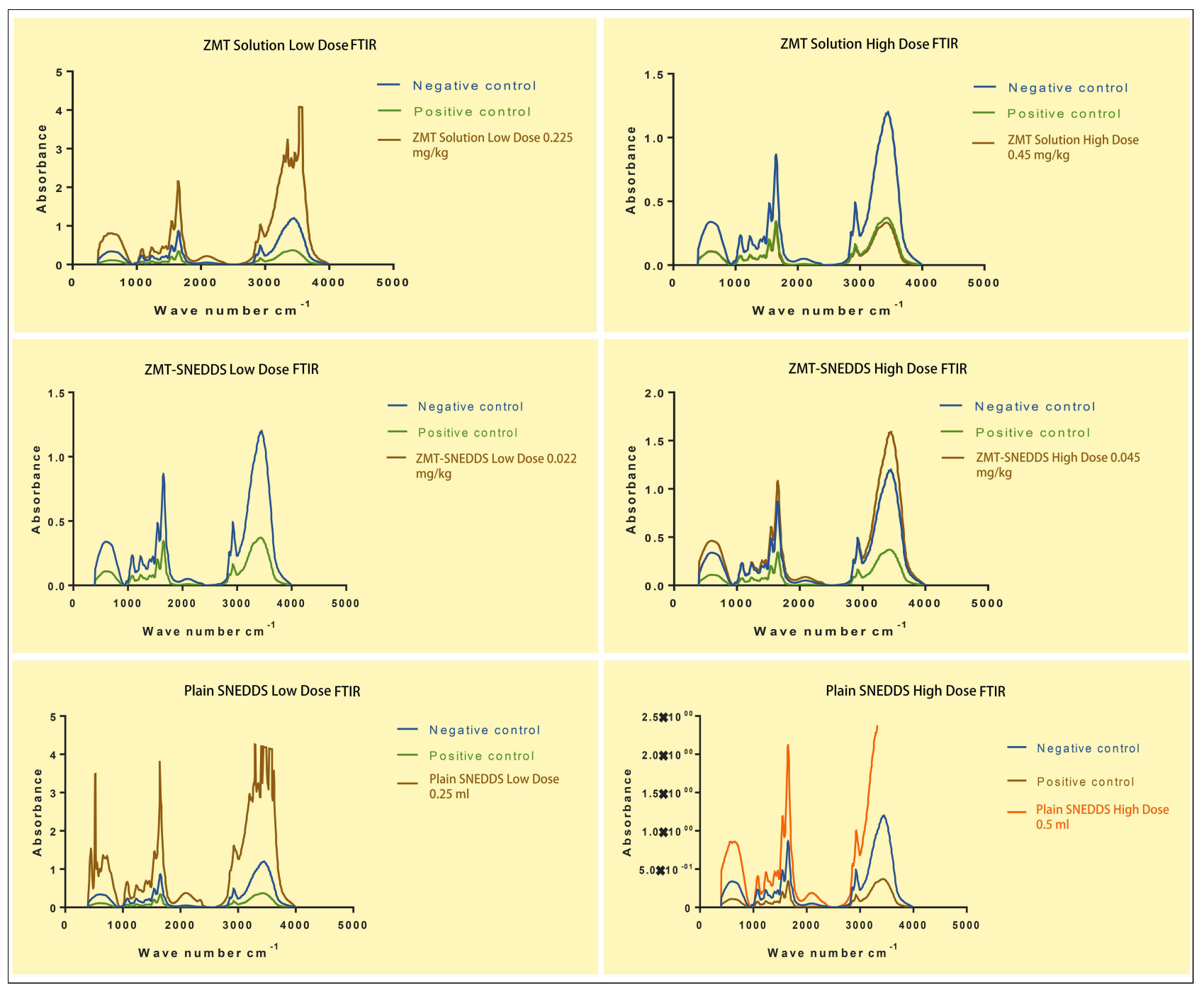

Figure 4 FTIR determination of structural and compositional changes in brain. 
states of biological molecules. ${ }^{47}$ FTIR spectroscopy (Figure 4), was done as a qualitative confirmatory test based on the established hypothesis of the serotonergic agonistic effect of ZMT, and to compare the effect of ZMT-SNEDDS on tryptophan (serotonin precursor) detection in brains of rats treated with both solution and SNEDDS, in addition to those treated with the plain SNEDDS containing lavender oil.

The average spectra of the negative control, positive control, and treated rats' brain cell homogenates in the $3000-4000 \mathrm{~cm}^{-1}$ and $1000-2000 \mathrm{~cm}^{-1}$ spectral regions are shown in Figure 4. The spectral parameters of the negative and positive control groups varied from each other noticeably, indicating that NTG-induced migraine caused marked structural and compositional changes in brain homogenates. The ZMT-SNEDDS high dose and plain SNEDDS treated groups spectra were close to the negative control group's spectra. No marked variations were observed between the negative control and ZMT-SNEDDS high dose treated groups. These results suggest the protective effect of SNEDDS against NTG-induced alterations. Since analogues of oleamides allow selective serotonin receptor subtype modulation, ${ }^{48}$ amide bands detected at $1000-2000 \mathrm{~cm}^{-1}$ give hints on proteins in the brain pointing to tryptophan which is a serotonin precursor.

UV-spectrophotometry (Figure 5) was carried out to elucidate the mechanism of structural changes in between groups. The negative control group spectrum profile showed that the optical absorption of proteins was at 200 nm. All groups had the same optical absorption wavelength but different peaks. There is no significant structural change between all groups.

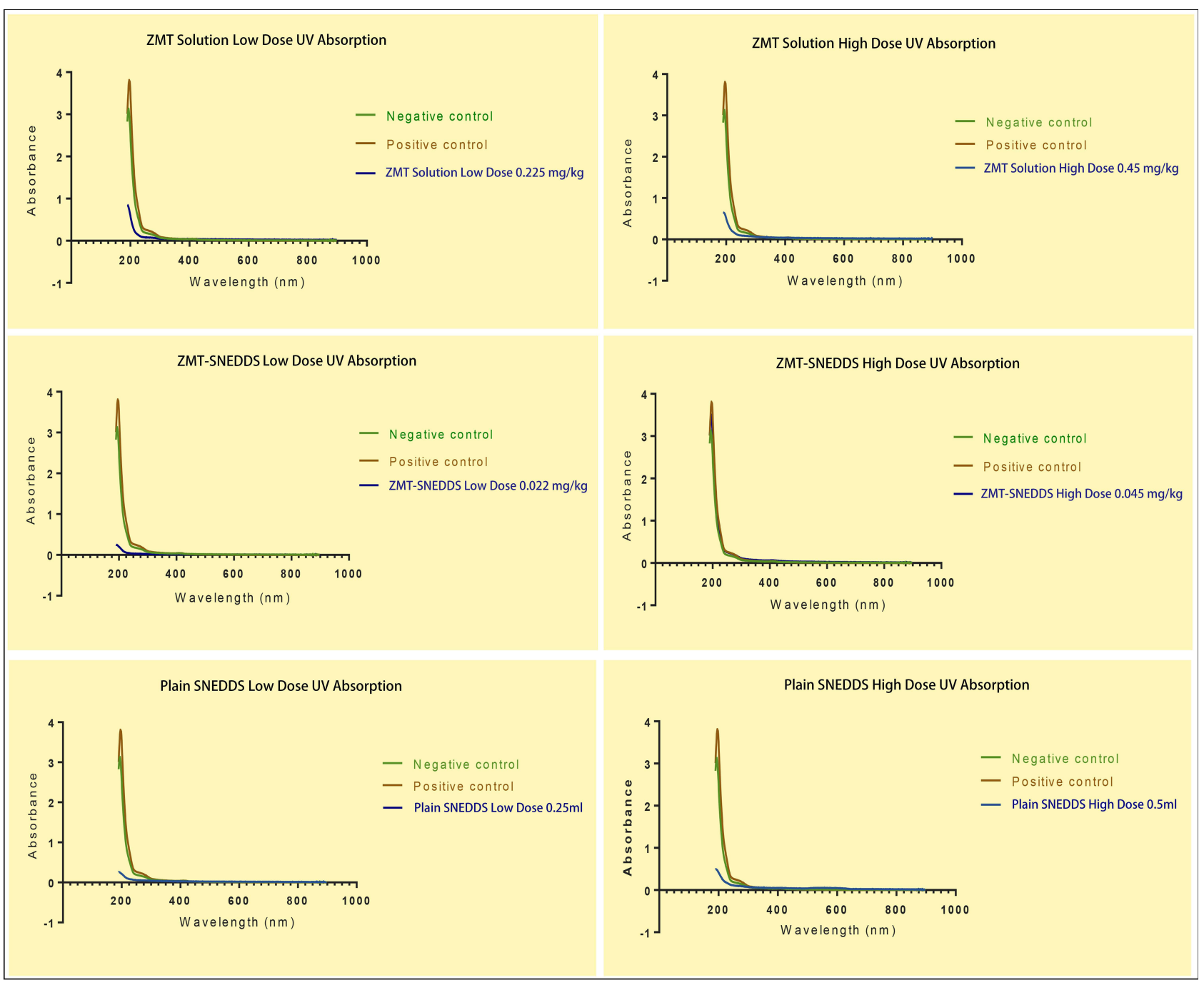

Figure 5 UV-spectrophotometric determination of metabolic changes in brain. 


\section{Histopathological and Immunohistochemical Examinations of Brain Tissues}

Histopathological and immunohistochemical studies confirmed the results of in-vivo efficacy experiments. Histopathological examination revealed that the best effect was achieved by the high dose of ZMT-SNEDDS as it showed normal histological architecture of cerebral cortex with normal arrangement of cells as negative control rats with score (0), followed by high dose of ZMT solution and low dose of ZMT-SNEDDS scoring 1, while ZMT solution low dose treated rats scored 2. On the other hand, animals given a low and high doses of plain SNEDDS had the same histological image as the untreated group scoring 3 .

Results of immunohistochemical studies of the cerebral cortex of negative control rats' specimens that were NSE stained revealed no detectable stain score (0), as illustrated in Figure S16. The positive control group showed score (3), in which most of the cortex was stained and characterized by an increase in NSE reactivity (Figure S17). Low dose ZMT solution scored (2) with a percentage of intense immunopositive neurons between 10 and 30\% (Figure S18). High dose ZMT solution and Low dose ZMT-SNEDDS scored (1) with index $>10 \%$ slightly immunopositive cells (Figures $\underline{\mathrm{S} 19}$ and $\mathrm{S20}$ ). On the other side, high ZMT-SNEDDS revealed no detectable stain score (0) (Figure S21). Low and high doses of plain SNEDDS displayed the same picture of induction group score (3) in which most of the cortex was stained (Figures S22 and S23).

The pain encountered by the migraine model in our study can be due to vasodilatation of cerebral blood vessels induced by NTG, which is an effective precursor of nitric oxide (NO) ${ }^{49}$ and also can be due to inflammation of meninges that are pain-sensitive due to trigeminal afferents irritation by neuronal pannexin-1, followed by Caspase-1 activation, then pro-inflammatory mediators release and nuclear factor kappa-B activation, finally inflammatory signals spread around the pia mater vessels. ${ }^{49}$ Moreover, NO can be produced significantly by the cerebrovascular endothelial cells and plays a crucial role in the inflammatory process of brain cells. ${ }^{50}$ However, these effects and the associated depression symptoms, as well as the histopathologic and immunohistochemical changes, were counteracted and ameliorated by the administration of ZMT solution and ZMT-SNEDDS in both doses. Moreover, the plain SNEDDS containing lavender oil showed a promising effect on these symptoms, which may enforce the hypothesis of the possibility of its synergistic effect with ZMT in the ZMT-SNEDDS formula.

\section{Conclusion}

ZMT is a selective serotonin agonist "triptan", used for the treatment of migraine, yet its reported side effects may reduce patient compliance. Therefore, it is worthwhile considering another formulation approach that offers the same efficacy in alleviating migraine symptoms but can be given in lower doses to reduce its side effects, which was achievable by ZMT-SNEDDS. The optimized ZMT-SNEDDS F5 exhibited nanosized globules with a better extent of permeation compared to that of ZMT solution. Its fast dissolution was successfully monitored in real-time by the integration of ATRFTIR technique in a continuous flow circulation. ZMT concentration in brain tissue attained from $\mathrm{F} 5$ was much lower than that from conventional ZMT solution for each dose level, whereas their effects were comparable, confirming F5 superiority and effectiveness. Lavender oil showed a promising effect in relieving pain, suggesting its value as a supplement for migraine treatment. Accordingly, the synergistic effect achieved by lavender oil in ZMT-SNEDDS offers a high potential effect in relieving migraine pain. However, all these promising effects of the novel preparation ZMT-SNEDDS containing lavender oil should be further subjected to clinical trials before administration to patients.

\section{Disclosure}

The authors report no conflicts of interest in this work.

\section{References}

1. Goadsby PJ, Holland PR, Martins-Oliveira M, Hoffmann J, Schankin C, Akerman S. Pathophysiology of migraine: a disorder of sensory processing. Physiol Rev. 2017;97:553-622. doi:10.1152/physrev.00034.2015.-Plaguing

2. Greco R, Bandiera T, Mangione AS, et al. Effects of peripheral FAAH blockade on NTG-induced hyperalgesia - Evaluation of URB937 in an animal model of migraine. Cephalalgia. 2015;35(12):1065-1076. doi: $10.1177 / 0333102414566862$

3. Abram JA, Patel P. Zolmitriptan. StatPearls [Internet]. Treasure Island (FL):StatPearls Publishing; 2021. Available from: https://www.ncbi. nlm.nih.gov/books/NBK557649/. Accessed September 7, 2021.

4. Abd-Elal RMA, Shamma RN, Rashed HM, Bendas ER. Trans-nasal zolmitriptan novasomes: in-vitro preparation, optimization and in-vivo evaluation of brain targeting efficiency. Drug Deliv. 2016;23 (9):3374-3386. doi:10.1080/10717544.2016.1183721

5. Kazi M, Al-Swairi M, Ahmad A, et al. Evaluation of self-nanoemulsifying drug delivery systems (SNEDDS) for poorly water-soluble talinolol: preparation, in vitro and in vivo assessment. Front Pharmacol. 2019;10(459):1-13. doi:10.3389/fphar.2019.00459

6. Rafie S, Namjoyan F, Golfakhrabadi F, Yousefbeyk F, Hassanzadeh A. Effect of lavender essential oil as a prophylactic therapy for migraine: a randomized controlled clinical trial. J Herb Med. 2016;6(1):18-23. doi:10.1016/j.hermed.2016.01.003 
7. Shakeel F, Alam P, Anwer MK, Alanazi SA, Alsarra IA, Alqarni MH. Wound healing evaluation of self-nanoemulsifying drug delivery system containing Piper cubeba essential oil. 3 Biotech. 2019;9 (3):82. doi:10.1007/s13205-019-1630-y

8. Eid SM, Abd El-Rahman MK, Elghobashy MR, Kelani KM. Attenuated Total Reflectance Fourier Transformation Infrared spectroscopy fingerprinted online monitoring of the kinetics of circulating Butyrylcholinesterase enzyme during metabolism of bambuterol. Anal Chim Acta. 2018;1005:70-80. doi:10.1016/j.aca.2017.12.011

9. Eid SM, Hassan SA, Nashat NW, Elghobashy MR, Abbas SS, Moustafa AA. Optimization of localized surface plasmon resonance hot spots in surface-enhanced infrared absorption spectroscopy aluminum substrate as an optical sensor coupled to chemometric tools for the purity assay of quinary mixtures. Microchim Acta. 2021;188 (195):1-14. doi:10.1007/s00604-021-04845-7

10. Champaneria RI, Gharia BK, Mishra AD, Shah SA. Development and VALIDATION of HPLC method for estimation of zolmitriptan in its pharmaceutical dosage form. Pharm Anal Acta. 2019;10(609):1-5. doi:10.35248/2153-2435.19.10.609

11. Amin MM, El Gazayerly ON, Abd El-Gawad NA, Abd El-Halim SM, El-Awdan SA. Effect of formulation variables on design, in vitro evaluation of valsartan SNEDDS and estimation of its antioxidant effect in adrenaline-induced acute myocardial infarction in rats. Pharm Dev Technol. 2015;21(8):909-920. doi:10.3109/ 10837450.2015.1078354

12. Su R, Yang L, Wang Y, et al. Formulation, development, and optimization of a novel octyldodecanol-based nanoemulsion for transdermal delivery of ceramide IIIB. Int $J$ Nanomedicine. 2017;12:5203-5221. doi:10.2147/IJN.S139975

13. Elsegaie D, Teaima M, Tadrous MI, Louis D, Maen V. Formulation and in-vitro characterization of Self Nano-emulsifying Drug Delivery System (SNEDDS) for enhanced solubility of candesartan cilexetil. Res J Pharm Technol. 2019;12(6):2628. doi:10.5958/0974360x.2019.00440.2

14. Kassem AA, Mohsen AM, Ahmed RS, Essam TM. Selfnanoemulsifying drug delivery system (SNEDDS) with enhanced solubilization of nystatin for treatment of oral candidiasis: design, optimization, in vitro and in vivo evaluation. $J$ Mol Liq. 2016;218:219-232. doi:10.1016/j.molliq.2016.02.081

15. El-halim SMA, Mamdouh MA, El-haddad AE, Soliman SM. Fabrication of anti-HSV-1 curcumin stabilized nanostructured proniosomal gel: molecular docking studies on thymidine kinase proteins. Sci Pharm. 2020;88(1):1-16. doi:10.3390/scipharm88010009

16. Sharma G, Beg S, Thanki K, et al. Systematic development of novel cationic self-nanoemulsifying drug delivery systems of candesartan cilexetil with enhanced biopharmaceutical performance. RSC $A d v$. 2015;5(87):71500-71513. doi:10.1039/c5ra11687b

17. Syukri Y, Martien R, Lukitaningsih E, Nugroho AE. Novel Self-Nano Emulsifying Drug Delivery System (SNEDDS) of andrographolide isolated from Andrographis paniculata Nees: characterization, in-vitro and in-vivo assessment. $J$ Drug Deliv Sci Technol. 2018;47:514-520. doi:10.1016/j.jddst.2018.06.014

18. Soliman SM, Sheta NM, Ibrahim BMM, El-Shawwa MM, El-Halim SMA. Novel intranasal drug delivery: geraniol charged polymeric mixed micelles for targeting cerebral insult as a result of ischaemia/ reperfusion. Pharmaceutics. 2020;12(1):76-97. doi:10.3390/ PHARMACEUTICS12010076

19. Guide for the care and use of laboratory animals. Institute of Laboratory Animal Resources (U.S.); Committee on Care and Use of Laboratory Animals; National Institutes of Health (U.S.) And Division of Research Resources. Bethesda, MD,: US Dept Heal Hum Serv Public Heal Serv Natl Insititutes Heal; 1985. Available from: https://www.worldcat.org/title/guide-for-the-care-and-use-oflaboratory-animals/oclc/14588475. Accessed September 7, 2021.
20. Paget GE, Barnes JM. Toxicity Test. In: Laurence DR, Bacharach AL, editors. Evaluation of Drug Activities. Massachusetts, New York: Academic Press; 1964:135-166.

21. Abou Baker DH, Ibrahim BMM, Hassan NS, Yousuf AF, El Gengaihi S. Exploiting Citrus aurantium seeds and their secondary metabolites in the management of Alzheimer disease. Toxicol Reports. 2020;7:723-729. doi:10.1016/j.toxrep.2020.06.001

22. Pradhan AA, Smith ML, McGuire B, Tarash I, Evans CJ, Charles A. Characterization of a novel model of chronic migraine. Pain. 2014;155(2):269-274. doi:10.1016/j.pain.2013.10.004

23. Al-Rawas SF, Poothrikovil RP, Abdelbasit KM, Delamont RS. The correlation between electroencephalography amplitude and interictal abnormalities: audit study. Sultan Qaboos Univ Med J. 2014;14(4): e473-e477.

24. Kowski AB, Holtkamp M. Electrically induced limbic seizures: preliminary findings in a rodent model. J Exp Neurosci. 2015;9(1):7-14. doi:10.4137/JEN.S23759

25. Demir P, Akkas SB, Severcan M, Zorlu F, Severcan F. Ionizing radiation induces structural and functional damage on the molecules of rat brain homogenate membranes: a Fourier transform infrared (FT-IR) spectroscopic study. Appl Spectrosc. 2015;69(1):154-164. doi:10.1366/13-07154

26. Taalat M, Aly E, Mohamed E, Ali M, Gaber H. Caffeine and nifedipine effect on cataract induced by selenite in rats. J Arab Soc Med Res. 2018;13(1):32. doi:10.4103/jasmr.jasmr_6_18

27. Bancroft JD, Gamble M. Theory and Practice of Histological Techniques. 7th ed. Edinburgh, London, Melbourne (NY): Churchill Livingstone; 2013.

28. Tang S, MacHaalani R, Waters KA. Immunolocalization of pro- and mature-brain derived neurotrophic factor (BDNF) and receptor TrkB in the human brainstem and hippocampus. Brain Res. 2010;1354:1-14. doi:10.1016/j.brainres.2010.07.051

29. Khan AW, Kotta S, Ansari SH, Sharma RK, Ali J. Selfnanoemulsifying drug delivery system (SNEDDS) of the poorly water-soluble grapefruit flavonoid Naringenin: design, characterization, in vitro and in vivo evaluation. Drug Deliv. 2015;22 (4):552-561. doi:10.3109/10717544.2013.878003

30. Lo JT, Lee TM, Chen BH. Nonionic microemulsions as solubilizers of hydrophobic drugs: solubilization of paclitaxel. Materials (Basel). 2016;9(9):761-774. doi:10.3390/ma9090761

31. Nasr A, Gardouh A, Ghorab M. Novel Solid Self-Nanoemulsifying Drug Delivery System (S-SNEDDS) for oral delivery of olmesartan medoxomil: design, formulation, pharmacokinetic and bioavailability evaluation. Pharmaceutics. 2016;8(20):1-29. doi:10.3390/pharmaceutics 8030020

32. Parmar N, Singla N, Amin S, Kohli K. Study of cosurfactant effect on nanoemulsifying area and development of lercanidipine loaded (SNEDDS) self nanoemulsifying drug delivery system. Colloids Surfaces B Biointerfaces. 2011;86(2):327-338. doi:10.1016/j. colsurfb.2011.04.016

33. Ansari MJ, Alnakhli M, Al-Otaibi T, et al. Formulation and evaluation of self-nanoemulsifying drug delivery system of brigatinib: improvement of solubility, in vitro release, ex-vivo permeation and anticancer activity. J Drug Deliv Sci Technol. 2021;61(article102204):E1-E68. doi:10.1016/j.jddst.2020.102204

34. Eid AM, El-Enshasy HA, Aziz R, Elmarzugi NA. The preparation and evaluation of self-nanoemulsifying systems containing Swietenia oil and an examination of its anti-inflammatory effects. Int J Nanomedicine. 2014;9(1):4685-4695. doi:10.2147/IJN.S66180

35. Murthy HN, Manohar SH, Naik M, Lee EJ, Paek KY. Physicochemical characteristics and antioxidant activity of Lavandula bipinnata seed oil. Int Food Res J. 2014;21(4):1473-1476.

36. Balakumar K, Vijaya C, Tamil N, Hari R, Abdu S. Self nanoemulsifying drug delivery system (SNEDDS) of Rosuvastatin calcium: design, formulation, bioavailability and pharmacokinetic evaluation. Colloids Surfaces B Biointerfaces. 2013;112:337-343. doi:10.1016/j. colsurfb.2013.08.025 
37. Sarheed O, Dibi M, Ramesh KVRNS. Studies on the effect of oil and surfactant on the formation of alginate-based $\mathrm{O} / \mathrm{W}$ lidocaine nanocarriers using nanoemulsion template. Pharmaceutics. 2020;12 (1223):1-8.

38. Zheng H, Mao L, Yang J, Zhang C, Miao S, Gao Y. Effect of oil content and emulsifier type on the properties and antioxidant activity of sea buckthorn oil-in-water emulsions. $J$ Food Qual. 2020;2020:1-8. doi:10.1155/2020/1540925

39. Alhalaweh A, Andersson S, Velaga SP. Preparation of zolmitriptan-chitosan microparticles by spray drying for nasal delivery. Eur J Pharm Sci. 2009;38(3):206-214. doi:10.1016/j. ejps.2009.07.003

40. Inugala S, Eedara BB, Sunkavalli S, et al. Solid self-nanoemulsifying drug delivery system (S-SNEDDS) of darunavir for improved dissolution and oral bioavailability: in vitro and in vivo evaluation. Eur J Pharm Sci. 2015;74:1-10. doi:10.1016/j.ejps.2015.03.024

41. Patel MH, Sawant KK. Self microemulsifying drug delivery system of lurasidone hydrochloride for enhanced oral bioavailability by lymphatic targeting: in vitro, Caco-2 cell line and in vivo evaluation. Eur J Pharm Sci. 2019;138(article105027):1-9. doi:10.1016/j.ejps.2019.105027

42. WebMD. Zomig oral: uses, side effects, interactions, pictures, warnings \& dosing. Available from: https:/www.webmd.com/ drugs/2/drug-5400/zomig-oral/details. Accessed September 7, 2021.

43. Sheng J, Liu S, Wang Y, Cui R, Zhang X. The link between depression and chronic pain: neural mechanisms in the brain. Neural Plast. 2017;2017. doi:10.1155/2017/9724371.
44. Li XY, Wan Y, Tang SJ, Guan Y, Wei F, Ma D. Maladaptive plasticity and neuropathic pain. Neural Plast. 2016;Article ID:1-2. doi:10.1155/2016/4842159

45. Haase J, Brown E. Integrating the monoamine, neurotrophin and cytokine hypotheses of depression - A central role for the serotonin transporter? Pharmacol Ther. 2015;147:1-11. doi:10.1016/j. pharmthera.2014.10.002

46. Sanna MD, Les F, Lopez V, Galeotti N. Lavender (Lavandula angustifolia Mill.) essential oil alleviates neuropathic pain in mice with spared nerve injury. Front Pharmacol. 2019;10(Article472):1-13. doi:10.3389/fphar.2019.00472

47. Cakmak G, Severcan M, Zorlu F, Severcan F. Structural and functional damages of whole body ionizing radiation on rat brain homogenate membranes and protective effect of amifostine. Int J Radiat Biol. 2016;92(12):837-848. doi:10.1080/09553002.2016.1230237

48. Boger DL, Patterson JE, Jin Q. Structural requirements for 5-HT2A and 5-HT1A serotonin receptor potentiation by the biologically active lipid oleamide. Proc Natl Acad Sci USA. 1998;95(8):4102-4107. doi:10.1073/pnas.95.8.4102

49. Steinmetzer J, Kupfer S, Gräfe S. pysisyphus: exploring potential energy surfaces in ground and excited states. Int J Quantum Chem. 2021;121(e 26390):1-18. doi:10.1002/qua.26390

50. Mostafa RE, Ibrahim BMM, Abdel Jaleel GA. Neuro-protective effects of Ginkgo biloba leaves extract on cerebral ischemia-reperfusion injury induced experimentally in ovariectomized rats. Int J Pharm Pharm Sci. 2016;8(8):237-242.
International Journal of Nanomedicine

\section{Publish your work in this journal}

The International Journal of Nanomedicine is an international, peerreviewed journal focusing on the application of nanotechnology in diagnostics, therapeutics, and drug delivery systems throughout the biomedical field. This journal is indexed on PubMed Central, MedLine, CAS, SciSearch ${ }^{\mathbb{}}$, Current Contents ${ }^{\mathbb{R}} /$ Clinical Medicine, $^{2}$

\section{Dovepress}

Journal Citation Reports/Science Edition, EMBase, Scopus and the Elsevier Bibliographic databases. The manuscript management system is completely online and includes a very quick and fair peer-review system, which is all easy to use. Visit http://www.dovepress.com/ testimonials.php to read real quotes from published authors. 